\title{
The Greenwich Graduate - Engaging With Students
}

\author{
Sally Alsford \\ Educational Development Unit
}

The Greenwich Graduate Initiative was launched in November 2010 with a series of presentations to and discussions with staff, led by Professor Simon Jarvis, Deputy Vice-Chancellor (Academic Development) (http://me-echo-1.gre.ac.uk:8080/ess/echo/presentation/49a7e0af-5e54-48af-b647-c519f379aed4).

Building on the experience of graduate attributes programmes in Australia (Bowden, 2000; Campbell, 2008); the involvement of university and students' unions' staff in the Change Academy

(www.heacademy.ac.uk/ourwork/universitiesandcolleges/changeacademy) and in consultation with UK higher education institutions (HEls) that have adopted this approach, attributes have been specified

in our vision for Greenwich graduates under the headings of scholarship and autonomy; creativity and enterprise; and cross-cultural and international awareness.

Under each of these headings, Greenwich graduates' attributes focus on three transferable skills: communication, critical thinking and problem solving (www.gre.ac.uk/emag/greenwichgraduate) Greenwich graduate initiatives are also strongly linked with employability strategies, which HEls are now required to publish for new and prospective students (www.hefce.ac.uk/pubs/circlets/2010/cl12 10/).

In February 2011, a Greenwich Graduate World Café event was hosted by the Educational Development Unit Student Forum, which was established in September 2010 to engage with students on learning, teaching, assessment, and student experience issues. Students were invited to discuss their experiences and aspirations at this event and academic staff were also invited to engage with students to understand what being a Greenwich graduate could - or should - mean. Over 50 participants attended. They talked, sketched, and wrote comments for nearly two hours.
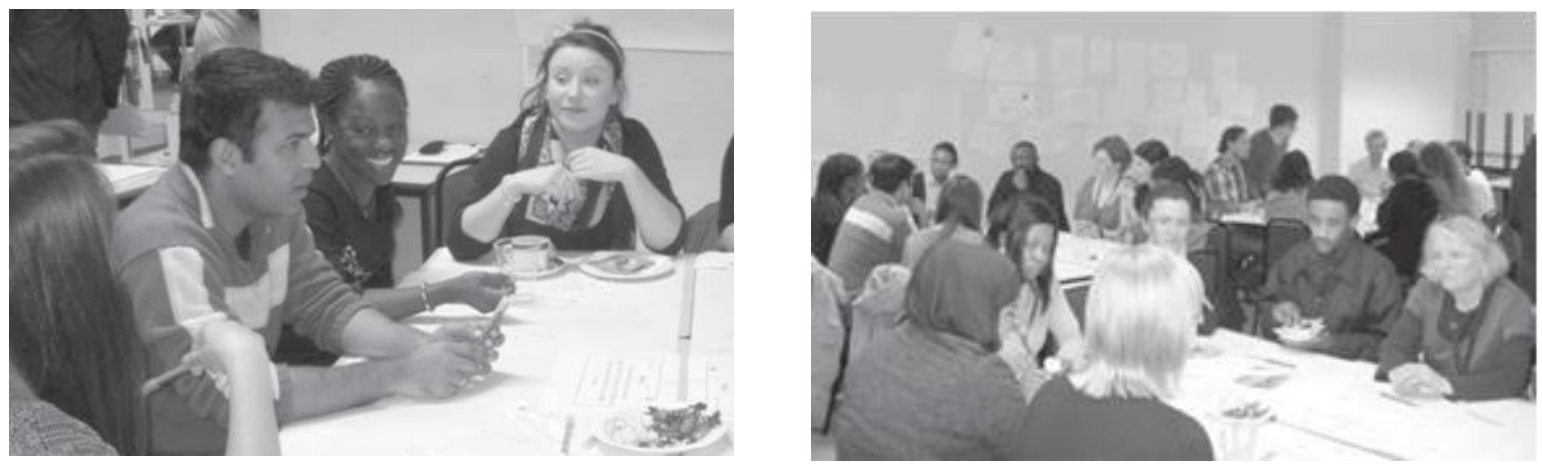

Figure 1 Students and staff participate in the Greenwich Graduate World Café, Greenwich Campus, 23 February 2011

In this report we seek to capture the discussions and views expressed at the event. It is based primarily on the comments and commentaries which were written down during the course of discussion, and aims to summarise rather than interpret.

On arrival, students were invited to draw something that expressed their impression of a Greenwich graduate, or what they thought being a Greenwich graduate would do for them. This exercise was designed as a quick, 
enjoyable and maybe unexpected way for students to think about and express their aspirations. Although there were alternative and more textual initial activities suggested, most chose this visual method of reflection.

Below are some examples of the students' representations of their hopes and aspirations as Greenwich graduates 'in process':
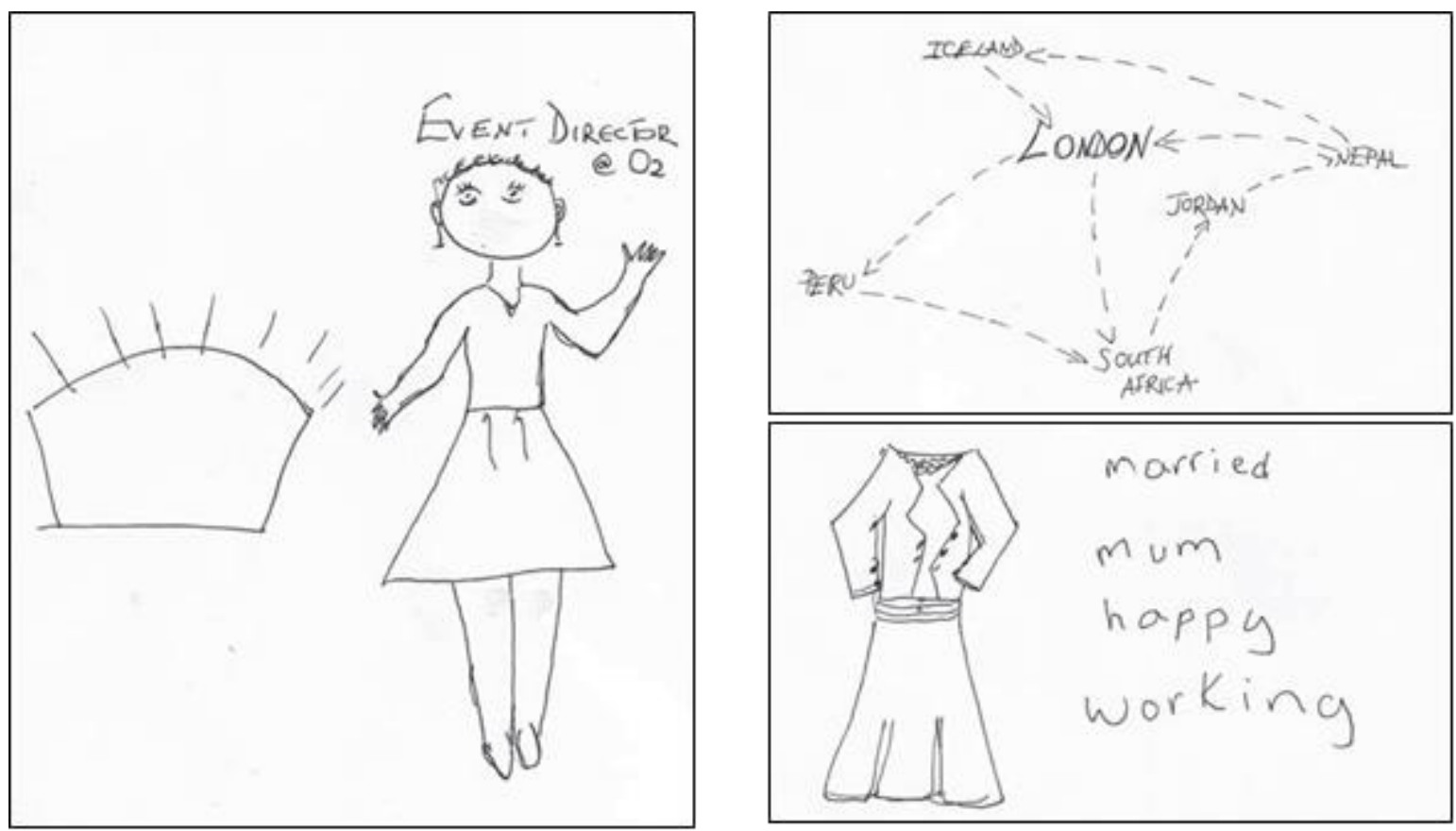

Figure 2 Drawings by students at the Greenwich Graduate World Café, Greenwich Campus, 23 February 2011. Other examples can be seen on the EDU Student Forum blog at http://blogs.gre.ac.uk/studentforum/2011/04/08/what-is-a-greenwich-graduate-like/.

World Café events aim to encourage informal conversation with food and music to create a relaxed atmosphere (Brown \& Isaacs, 2005).

Participants spend time at a number of discussion tables, each with a different theme or question designed to prompt the sharing of experience and ideas, and to focus discussion. Some of the discussion is captured by participants writing or drawing on paper tablecloths.

The main discussions at the World Café event focused on questions presented at five discussion tables, each of which was labelled with a statement based on the Greenwich graduate attributes.

\section{The five statements:}

A Greenwich graduate should:

1. Be able to think independently and analytically about their subject or professional practice and beyond.

2. Be fluent and articulate in oral and written communication.

3. Be able to recognise and respond effectively to unfamiliar situations, demonstrating resourcefulness and good judgement.

4. Be able to operate effectively across a range of different cultural and social contexts.

5. Appreciate the importance of behaving sustainably and ethically in a global context.

Participants discussed the statement on their table and were asked to consider: 
Compass: The Journal of Learning and Teaching at the University of Greenwich Issue 4, 2012

- whether they agreed with it

- what it meant to them in their own words

- the key moments or experiences that helped (or didn't help)

- examples of how the university could help - or has helped - in development of these skills?

The word cloud below captures key words from the discussions which developed around each of the five statements. It was generated from a transcript of the notes written on the tables. The relative sizes of the words in these graphic representations indicate how frequently they appeared in the comments, with the largest words being those most used (www.wordle.net).

Statement 1: A Greenwich graduate should be able to think independently and analytically about their subject or professional practice and beyond.

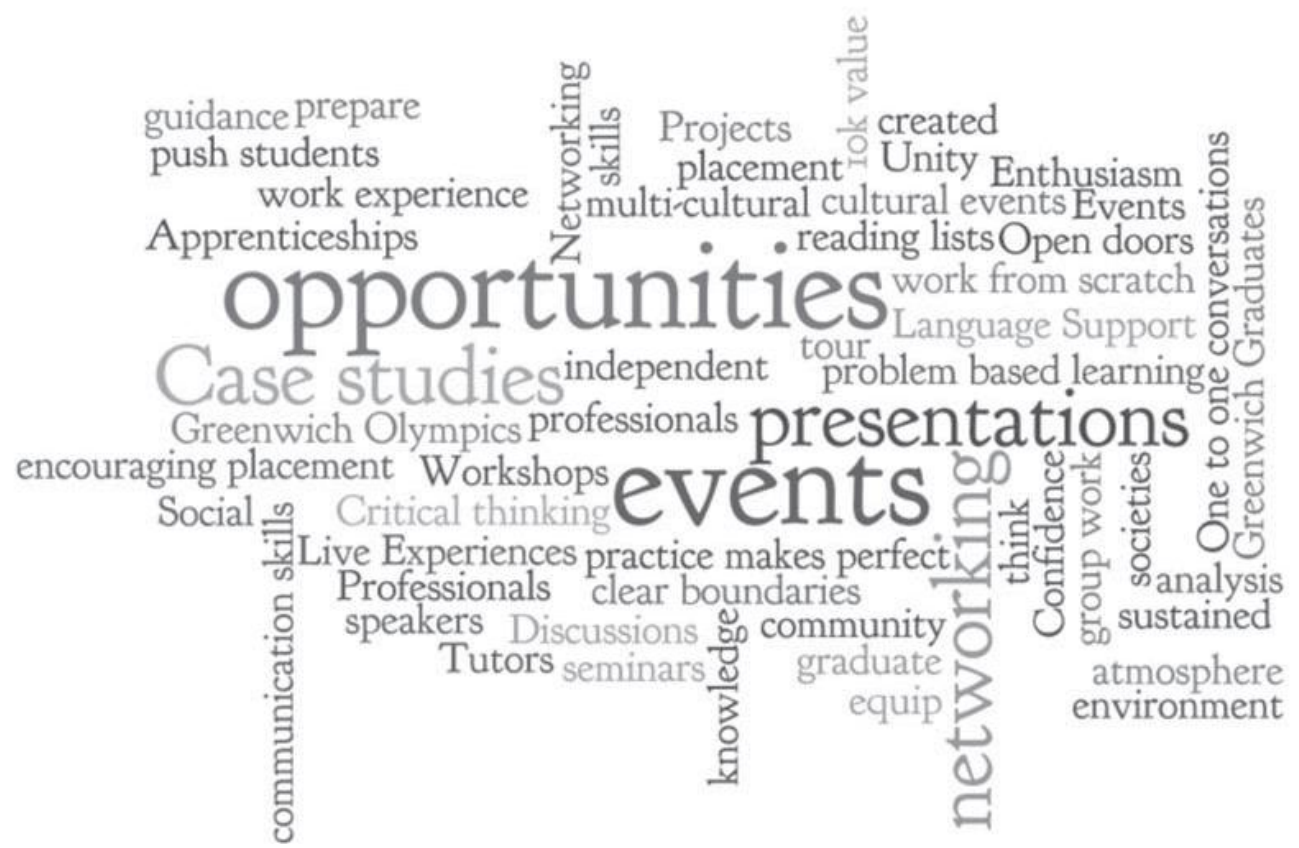

Discussion of the first statement included the strong endorsement: "This is the minimum that you would expect from a graduate, they shouldn't have a degree if they can't." Working on case studies, projects, group work and presentations were identified as ways of acquiring this attribute and students asked for more opportunities for placements, work experience and input from professionals. "Encourage students to seek apprenticeships/work experience, under their own steam - placements really 'push' students, and help gain knowledge and prepare you." There was a clear emphasis on the need for social involvement and networking with students, staff and professionals; for events; for support to prepare students; to foster community and enthusiasm; and to develop skills. The responsibility of students to be motivated was also noted as "fundamental". 
Statement 2: A Greenwich graduate should be fluent and articulate in oral and written communication.

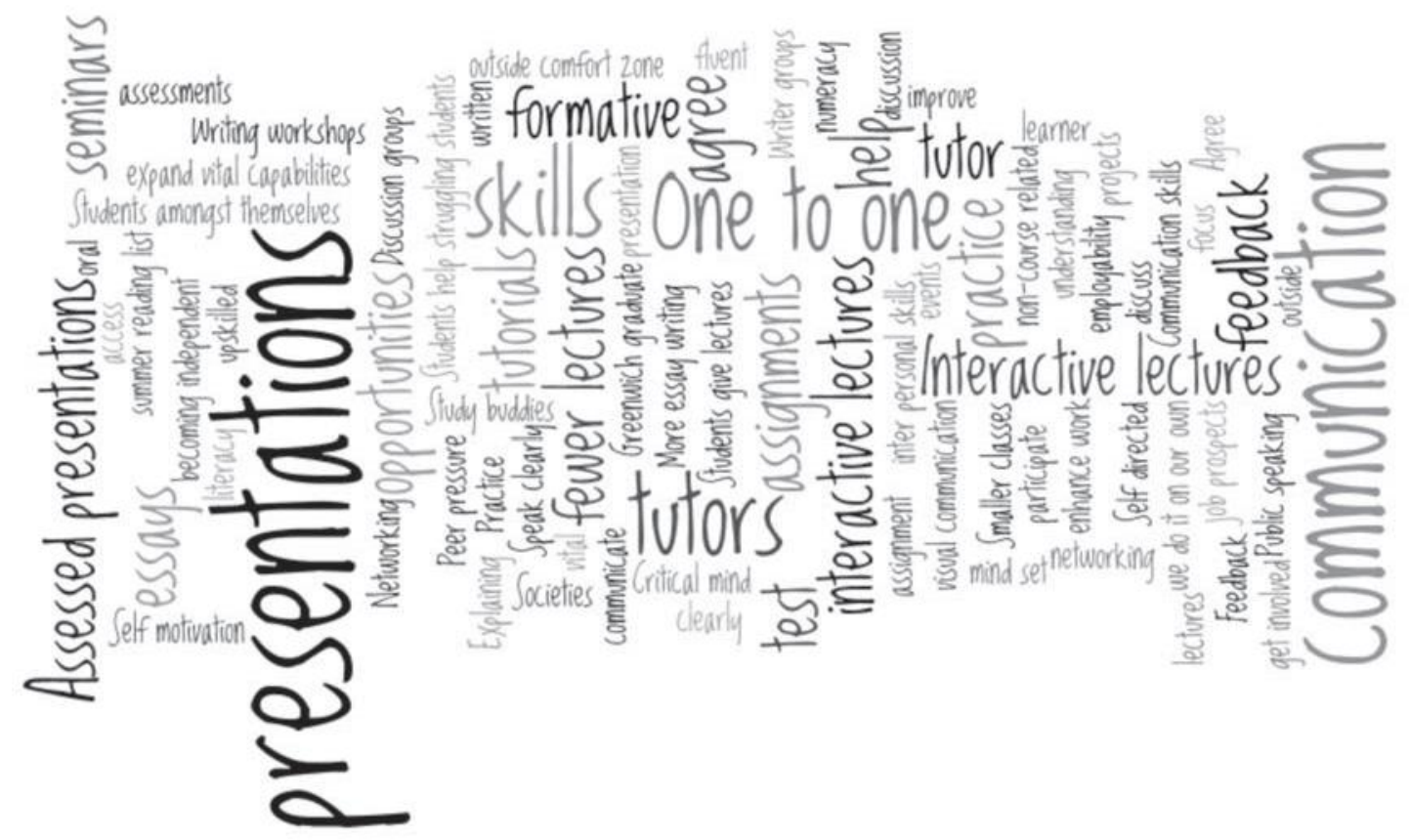

Discussion of the second statement focused on interactivity between students and tutors, and between students and their peers, with an emphasis on the need for networking. There was a strong emphasis on the importance and value of seminars, group work, and assessed presentations. The development of communication skills and a desire for interactive lectures was clearly expressed: one second year student described the latter as "essential". There was a balance in the comments made between the need for more tutorials, more seminars, feedback from tutors and one-to-one work -"Smaller classes and tutor involvement can mean the difference between a 1st or a 2.1 or even a !!! eeek" - and the need for students to be self-motivated and develop independence as learners. Another student commented on the need to be "able to... not always follow structures." 
Statement 3: A Greenwich graduate should be able to recognise and respond effectively to unfamiliar situations, demonstrating resourcefulness and good judgement.

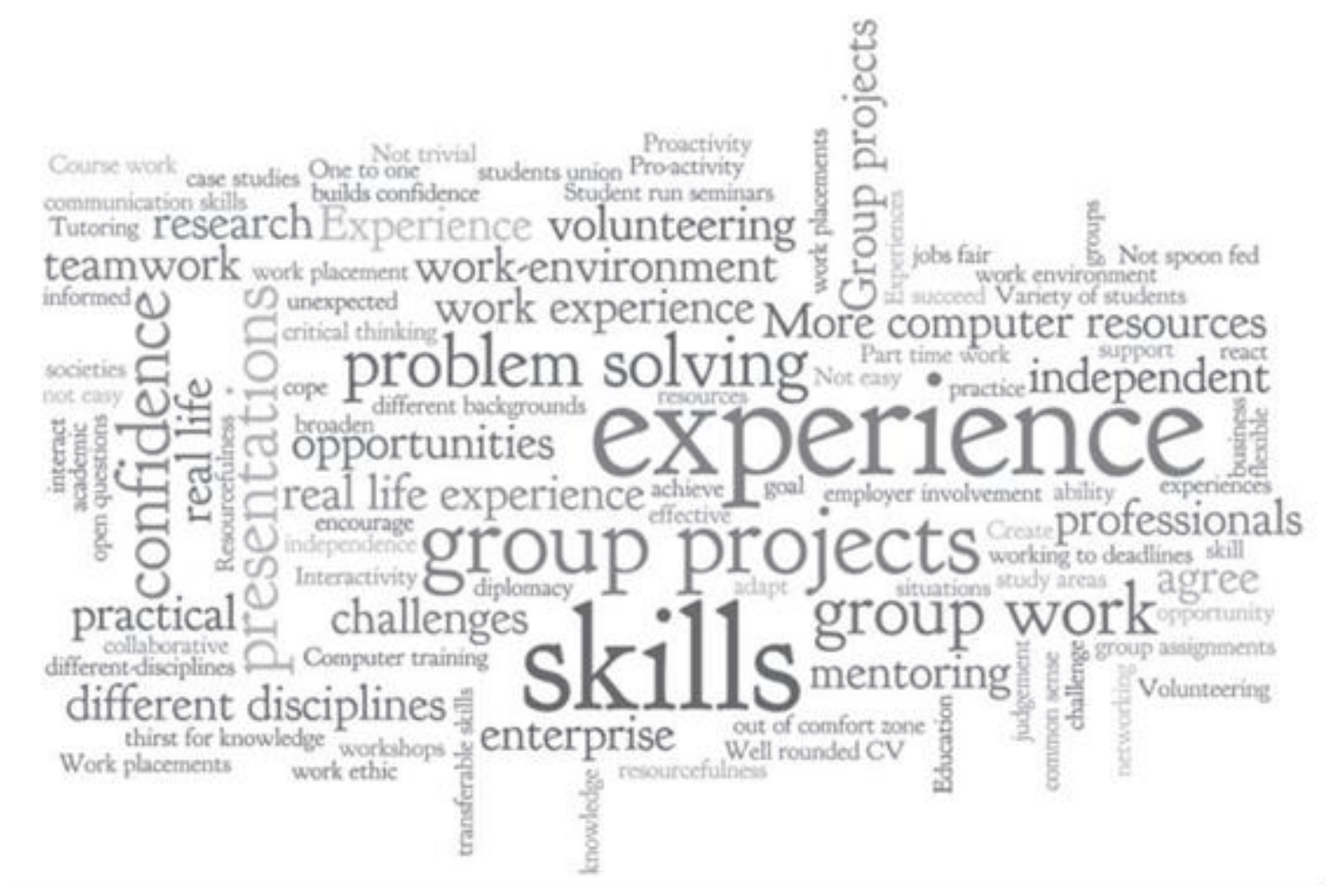

Participants discussing Statement 3 suggested that while students find this challenging, they do see the need to develop such attributes: "Not easy at the beginning. Should at least be prepared through being given challenging tasks to build my confidence." Suggestions for how to achieve this included strong emphasis on work placements, volunteering, 'real-life' experiences, learning from professionals and case studies: "Maybe real life situations would be a good challenge, for example, work placements that are compulsory." "This statement means to me that students should be able to cope with any situation even if unexpected....intelligent problem solving is a great skill." Group work, projects and presentations were mentioned frequently as ways to help students develop such skills. Independence and confidence - "stepping outside your comfort zone" - and the desire for support in the form of tutorials, mentoring, workshops and one-to-one sessions were also expressed. Interactivity was identified as important, with a number of suggestions that interaction with different disciplines could help to achieve this goal.

Statement 4: A Greenwich graduate should be able to operate effectively across a range of different cultural and social contexts. 


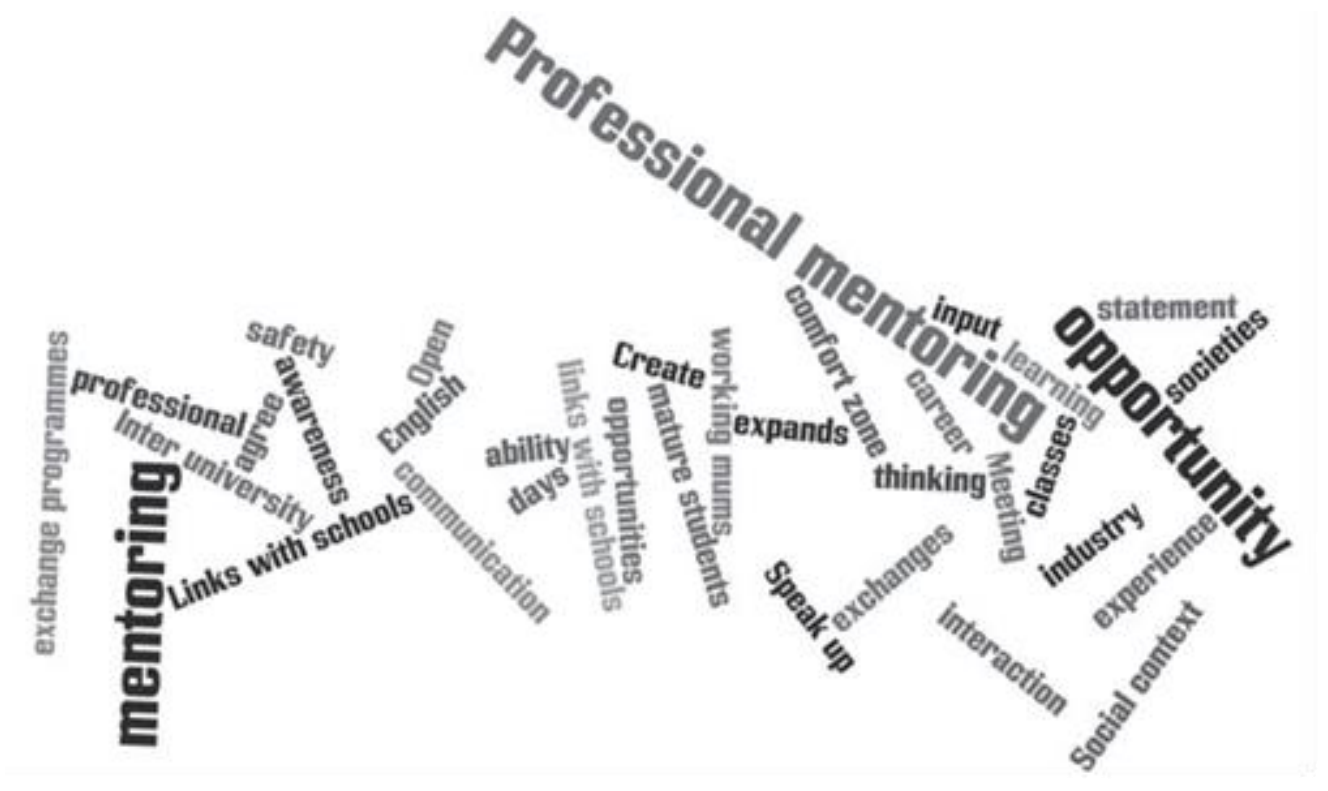

Participants agreed that the attribute expressed in Statement 4 was very important: it could "Open you up, expand your thinking, in the context of opportunities" with the need to be "careful this does not decline". Networking, communication, student exchanges and societies were identified ways to create opportunities for interaction across the diverse range of students at Greenwich, and: "How about inter-university exchange programmes?" Discussion at this table emphasised the value of mentoring, particularly mentoring by professionals, and of creating links across and between Schools.

Statement 5: A Greenwich graduate should appreciate the importance of behaving sustainably and ethically in a global context.

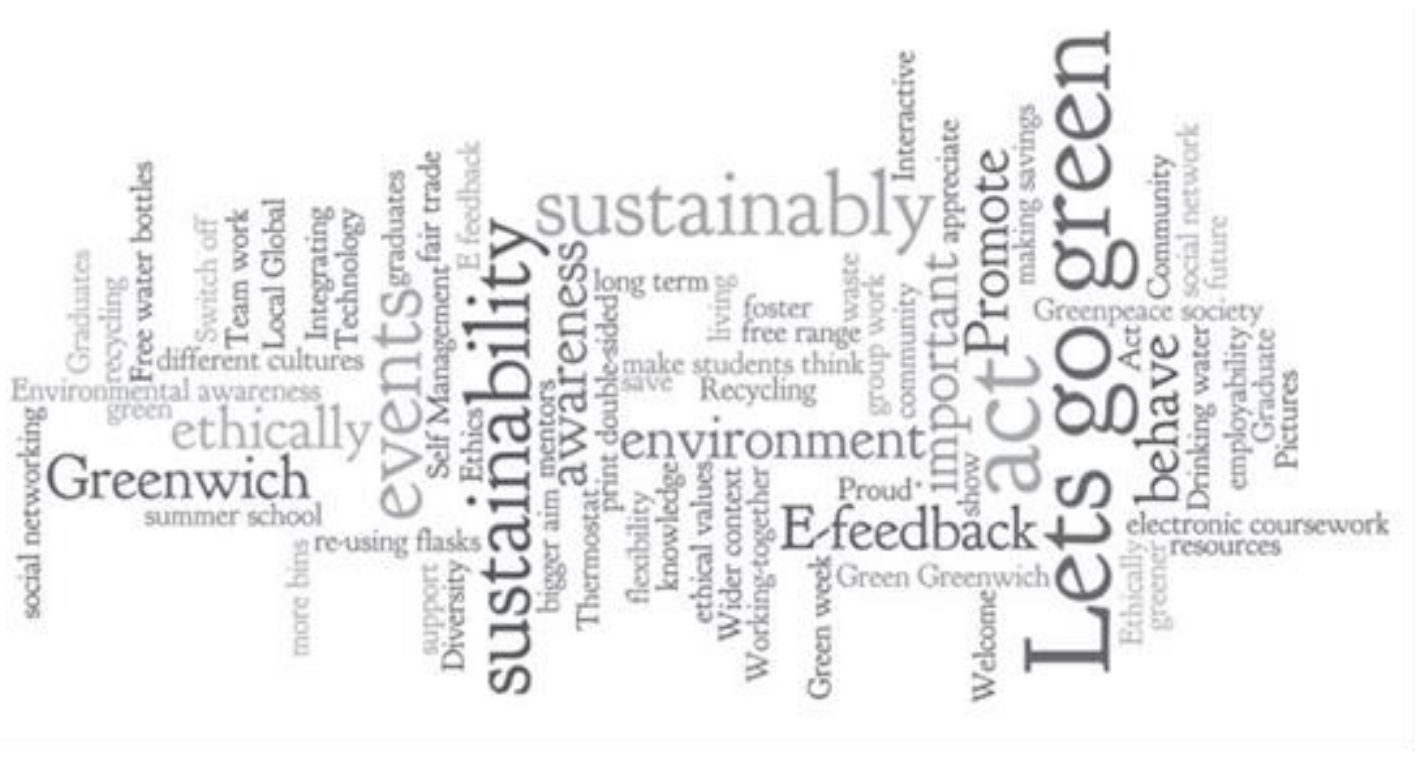

Statement 5 prompted a lively discussion with some disagreement expressed: this attribute was seen as not going far enough. Students felt that "a Greenwich graduate should not only appreciate the importance of behaving sustainably and ethically but act sustainably and ethically". Students were confident that most were environmentally aware, and would welcome more opportunities to translate awareness into action. 
The written comments captured ideas for how the university could develop these attributes, including the importance of working collaboratively, supporting interactivity and networking to raise awareness (e.g. through events, societies and mentoring). Specific suggestions were made including: free long-life water bottles; electronic course materials, coursework submission and feedback; double-sided printing; thermostats in student accommodation; switching off computers at night; a Greenwich Greenpeace society; more recycling bins; and drinking water more widely available on campus.

A number of key themes emerged from discussions around all five of the statements. The themes are listed below in no particular order):

- Students expressed a need for one-to-one discussion with tutors, more tutorials and more feedback to help them understand what is wanted and how to improve their work

- Students have responsibility for their self-motivation and willingness to learn and need to develop as independent learners

- Students want more interactive and smaller classes, and more group work, seminars, project work and discussion groups, including students leading some of these activities

- More formative work and more feedback are needed - including electronic feedback

- There is a strong demand for a more social environment and more support for and advertising of social opportunities, including events, networking, societies, cross-School links and cultural activities

- Language support is necessary (for ESL students), as is support for writing skills for all/any student

- All students should have to do presentations

- Work placements and volunteering are extremely important and need to be encouraged and supported

- Interaction with other disciplines could have significant positive outcomes in relation to graduate attributes

- Mentoring - both peer mentoring and mentoring by professionals - is extremely valuable

- More interactivity, in the way the university communicates with students, is needed.

The Greenwich Graduate World Café event was publicised through the EDU Student Forum, by e-mail and portal announcements, and with flyers to student volunteers. However, the majority of students came because they were invited by their tutors. This reinforces previous experience of focus group events which suggests that tutorial encouragement is one of the strongest motivators for students. One aspect that featured strongly in students' positive evaluation of the event was the open and equal discussion between staff and students: "Tutors being at the same level as students", "staff and students are sharing ideas".

As the Greenwich Graduate linitiative is new to staff as well as to students, it is hoped that the process and the content of the event provided a valuable stimulant and catalyst for future reflection and development, which others may wish to adopt. Most, though not all, of the students involved were based at the Greenwich Campus and thus represented its three Schools: Business; Computing \& Mathematical Sciences; and Humanities \& Social Sciences. Staff and students from all three Schools and levels participated. Future iterations of this model might be usefully based not only on other campuses but also perhaps within Schools, departments and/or programmes.

Further feedback and comment was recorded in posts and comments on the EDU Student Forum blog (http://blogs.gre.ac.uk/studentforum). Some of the student volunteers who worked with us on this event also became part of the team that organised the university's annual conferences. Student participation in this event might therefore be seen as an opportunity to further develop Greenwich graduate attributes at an individual level. 
Compass: The Journal of Learning and Teaching at the University of Greenwich Issue 4, 2012

The university plans to maintain and extend this dialogue and partnership as we articulate what we are already doing well, and what needs to change, within the framework of the Greenwich Graduate Initiative. The World Café event was a positive step forward and will be followed by more work with students over the coming academic year.

\section{References}

Bowden, J. et al. (2000) Generic Capabilities of ATN Universities' Graduates. Teaching \& Learning Committee, Australian Technology Network.

Brown, J., and Isaacs, D. (2005) The World Café: Shaping Our Futures Through Conversations That Matter.

Berrett-Koehler. Available at: <www.theworldcafe.com > [Accessed 8 April 2011]

www.palgrave-journals.com/ejis/journal/v1/n6/pdf/ejis199217a.html www.wordle.net

Campbell, A. (2008) Developing Graduate Attributes. VDM Verlag Dr. Muller Aktiengesellschaft \& Co. KG. 